Total organic carbon, rock-eval pyrolysis, and vitrinite reflectance data of cuttings from the Home $0 i 1$ Company Bush Federal No. 1 well 


\section{GEOCHEMICAL DATA FOR}

BUSH FEDERAL \#1

\begin{tabular}{|c|c|c|c|c|c|c|c|c|}
\hline DEPTH $(f t)$ & FORMATION & $\begin{array}{c}S_{1} \\
(\mathrm{~kg} / \mathrm{t})\end{array}$ & $\begin{array}{c}s_{2} \\
(k g / t)\end{array}$ & $\begin{array}{l}\text { TOC } \\
(\%)\end{array}$ & $\begin{array}{l}\text { PRODUCTION } \\
\text { Index }\end{array}$ & $\begin{array}{l}\text { HYDROGEN } \\
\text { Index }\end{array}$ & $\begin{array}{l}T_{\text {MAX }} \\
\left({ }^{\circ} \mathrm{C}\right)\end{array}$ & $\% \mathbf{R}_{\mathbf{o}}$ \\
\hline $9300-9400$ & Shale Wall & 0.41 & 0.72 & 0.76 & 0.37 & 94 & 455 & - \\
\hline 9400.9500 & Shale Wall & 0.71 & 1.09 & 0.75 & 0.39 & 145 & 450 & 0.99 \\
\hline $9500-9600$ & Shale Wall & 0.84 & 1.30 & 0.95 & 0.39 & 136 & 451 & - \\
\hline $9600-9700$ & Shale Wall & 1.14 & 1.78 & 1.15 & 0.39 & 41 & 451 & - \\
\hline $10800-10900$ & HRZ & 0.78 & 1.05 & 0.74 & 0.43 & 60 & 456 & - \\
\hline $10900-11000$ & HRZ & 0.87 & 0.72 & 1.57 & 0.55 & 35 & 457 & - \\
\hline
\end{tabular}


